\title{
Common Pattern of Two Distinct Types of Colony- stimulating Factor in Human Tissues and Cultured Cells
}

\author{
Ming-CHI Wu and Adel A. Yunis, Departments of Medicine and Biochemistry, \\ University of Miami School of Medicine, Miami, Florida 33101; Howard Hughes \\ Medical Institute, Miami, Florida 3:3133
}

\begin{abstract}
A B S T RACT Conditioned media prepared from human lung, placenta, peripheral leukocytes, cultured human pancreatic carcinoma cells, and cultured cervical carcinoma cells exhibit a common pattern of two distinct colony-stimulating factors (CSF) separable by isoelectrofocusing. Type I CSF appears polydisperse on isoelectrofocusing, showing multiple peaks with an isoelectric point of 3.6-4.7 and mol wt 50,000. It has a much higher activity in mouse than in human bone marrow, and stimulates the formation of predominately macrophage colonies. Type II CSF has an isoelectric point of 5.7 and mol wt 27,000 and exhibits higher activity in human than in mouse marrow, yielding predominately granulocytic colonies.
\end{abstract}

\section{INTRODUCTION}

Colony-stimulating factor $(\mathrm{CSF})^{1}$ is a protein required for the in vitro growth of granulocyte and macrophage colonies from bone marrow (1) and has been postulated to function as a granulopoietin in vivo. CSF is found widely distributed in many tissues and has been purified from several murine sources (2-5), human urine (6), and human lung (7). More recently, in our constant search for practical sources of human CSF, we discovered that a human pancreatic carcinoma cell line (MIA PaCa-2) established in our laboratory (8) secretes relatively large amounts of CSF into the medium. Upon purification, two distinct CSF activities were found separable by isoelectrofocusing (9), and different with respect to their isoelectric point (PI), molecular weight, and relative activity in mouse vs. human bone marrow. This pattern had not been previously observed in our work with human lung CSF (7). However, isoelectrofocusing was not employed as the

\footnotetext{
Dr. Yunis is a Howard Hughes Investigator.

Received for publication 12 November 1979 and in revised form 20 December 1979.

${ }^{1}$ Abbreviations used in this paper: CSF, colony-stimulating factor; DME, Dulbecco's modified Eagle's medium; DME-HS, DME supplemented with 5\% human serum; PI, isoelectric point.
}

initial step in the purification of human lung CSF. Accordingly, when CSF from human lung-conditioned medium was subjected to the same procedures applied to the MIA PaCa-2 CSF, a similar pattern of two distinct types of CSF was observed. The present work suggests that this pattern may be common to all human tissues.

\section{METHODS}

Tissue culture media were purchased from Grand Island Biological Co., Grand Island, N. Y.; Ultrogel, Ampholine, and other isoelectrofocusing and gel filtration media were from L.KB Instruments, Inc., Rockville, Md. All other chemicals were of reagent grade.

Preparation of conditioned medium. Human lung conditioned medium was prepared as described previously (10), and human placenta conditioned medium was prepared exactly the same way as human lung conditioned medium. Human pancreatic carcinoma (MIA PaCa-2) cell line was established and maintained in this laboratory (8). Human cervical carcinoma cell line was established recently in this laboratory. The procedure for the preparation of serum-free conditioned medium has been reported (11). Peripheral blood leukocyte conditioned medium was prepared as follows: heparinized blood from a normal donor was mixed with an equal volume of isotonic saline solution, layered over a FicollHypaque gradient (lymphocyte separation media; Bionetics I aboratory Products, Litton Bionetics Inc., Kensington, Md.), and centrifuged at $400 \mathrm{~g}$ for $40 \mathrm{~min}$. The light density cells $(<1.078)$ at interface were collected and washed with Dulbecco's modified Eagle's medium (I)ME) supplemented with $5 \%$ human serum (DME-HS). The washed interface cells were placed in tissue culture plates at a concentration of $2-3 \times 10^{6}$ cells $/ \mathrm{ml}$ of DME-HS and incubated for $2 \mathrm{~h}$ at $37^{\circ} \mathrm{C}$ in $5 \% \mathrm{CO}_{2}$ atmosphere. The nonadherent cells were removed and the plates rinsed with DME-HS and incubated in DME-HS for $7 \mathrm{~d}$. The conditioned medium was removed, centrifuged to remove cell debris, dialyzed against distilled water overnight, and sterilized by filtration.

Assay of CSF. The standard assay method used in this laboratory has been described previously (10). Human bone marrow cells were obtained from the posterior iliac crest of normal volunteers and were further fractionated by FicollHypaque method followed by removal of the adherent cells (12). Colonies were scored on day 7.

Preparative isoelectrofocusing. Serum-free conditioned medium was concentrated by Amicon ultrafiltration (PM10 membrane, Amicon Corp., Lexington, Mass.) to $3.0 \mathrm{ml}$ and 
dialyzed against distilled water overnight (three times). The sample was subjected to flat-bed preparative isoelectrofocusing according to procedures described previously (9).

Gel filtration. The human active CSF fractions (.Xos. 28-30) (Fig. 1) or mouse active CSF fractions (Nos. 1-20) from preparative isoelectrofocusing were pooled, concentrated by Amicon ultrafiltration to $1.5 \mathrm{ml}$, and then applied to an Ultrogel AcA 44 column (LKB Instruments, Inc.; 1.1 $\times 110 \mathrm{~mm}$, column volume, $110 \mathrm{ml}$, real volume) for gel filtration. The column was previously equilibrated with $0.1 \mathrm{M}$ $\mathrm{NaCl}$ solution containing $0.01 \%$ Tween-20, $0.01 \% \mathrm{NaN}_{3}, 5$ $\mu \mathrm{g} / \mathrm{ml}$ streptomycin, and $5 \mathrm{U} / \mathrm{ml}$ penicillin eluted with the same solution. Protein profile and CSF activity were measured as above.

Morphological analysis. The study of colony morphology in the assay plates was conducted by a new technique recently developed in our laboratory. The soft agar plates containing colonies were first fixed with $30 \%$ acetic acid in absolute ethanol for $30 \mathrm{~min}$ at room temperature. The plate was then rinsed sequentially with 100,80 , and $50 \%$ ethanol. The fixed agar layer was removed by floating in water and dried at $60^{\circ} \mathrm{C}$ for $2 \mathrm{~h}$. The dried thin film was stained with alumn hematoxylin for $15 \mathrm{~min}$ and rinsed with running water to remove excess dye. The film was then air-dried and examined under the microscope for individual cell morphology within the colonies.

\section{RESULTS}

Separation of two types of CSF. Fig. 1 shows the isoelectrofocusing profile of concentrated conditioned medium from human lung (A), human placenta (B), cultured human pancreatic carcinoma cells $(C)$, cultured cervical carcinoma cells (D), and human leukocytes (E), as assaved on human and mouse bone marrow.

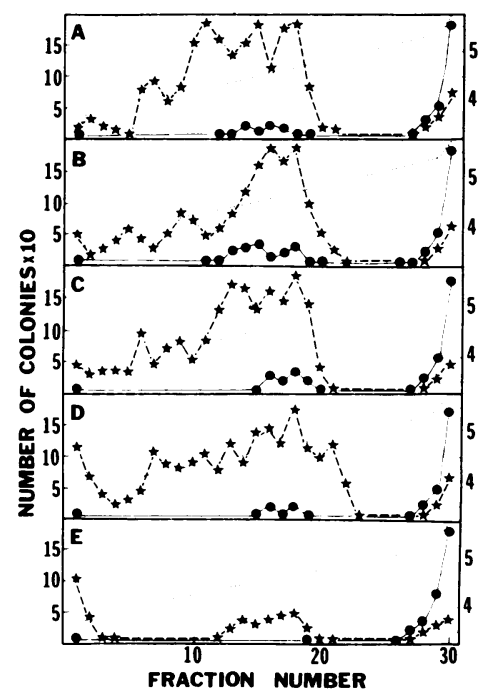

FIGURE 1 Isoelectrofocusing. Serum-free conditioned media from different sources were concentrated and applied to a $100-\mathrm{ml}$ gel bed. Isoelectrofocusing was conducted as described in Methods: (A) human lung, (B) human placenta, (C) MIA PaCa-2 cells, (D) cervical carcinoma cells, (E) human leukocytes. Activity in mouse marrow, $\star$; activity in human inarrow, ; $\mathrm{pH}$, dotted line.

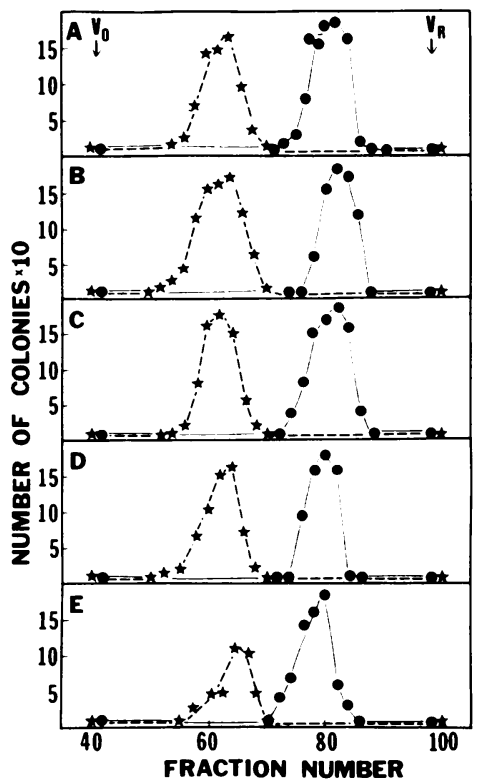

Figure 2 Gel filtration chromatography. Mouse and human active fractions from Fig. 1 were pooled, separately concentrated, and applied to an Ultrogel AcA 44 column as described in the Methods: (A) human lung, (B) human placenta, (C) MIA PaCa-2 cells, (D) cervical carcinoma cells, (E) human leukocytes. Activity in mouse marrow, $\star$; activity in human marrow, $\mathrm{V}_{\mathrm{O}}$, void volume; $\mathrm{V}_{\mathrm{R}}$, retention volume.

In each case two clearly separable types of CSF are observed. Type I appears heterogeneous, composed of multiple peaks and a broad PI in the range of 3.7-4.7, and exhibits much greater activity in mouse than in human bone marrow. A minor deviation from this pattern is seen in the case of leukocyte conditioned medium where type I CSF exhibits a lower PI probably as the result of a higher sialic acid content, and has a lower ratio of human:mouse marrow activity than type I CSF from the other human tissues. Type II CSF appears at the end of the profile, had a PI of 5.8-6.0, and is more active in human than in mouse marrow. A rerun of CSF II from all five sources on isoelectrofocusing at a pH range of 4-6.5 has yielded a PI of 5.7.

Gel filtration profile. The active fractions of type I and type II CSF from each isoelectrofocusing profile in Fig. 1 were pooled separately, concentrated, and applied to an Ultrogel AcA 44 column for gel filtration. The same column was used throughout. The filtration profiles are shown in Fig. 2. Type I CSF, which is heterogeneous on isoelectrofocusing (PI 3.6-4.7), emerges essentially as one peak with mol wt 50,000 . Type II CSF shows mol wt 27,000. Treatment of either CSF with neuraminidase in $0.05 \mathrm{M}$ sodium acetate buffer, $\mathrm{pH} 5.0$, or mercaptoethanol $(0.001 \mathrm{M})$ in phosphate-buffered saline, $\mathrm{pH} 7.4$, at room temperatures for $2 \mathrm{~h}$ does not alter the molecular weight significantly. 
TABLE I

Morphology of Colonies Stimulated by Types I and II CSF from Different Sources

\begin{tabular}{llrrr}
\hline & & \multicolumn{3}{c}{ Number of colonies } \\
\cline { 3 - 5 } Source of CSF & $\begin{array}{c}\text { Source of } \\
\text { marrow }\end{array}$ & $\begin{array}{c}\text { Granulo- } \\
\text { cyte }\end{array}$ & $\begin{array}{c}\text { Macro- } \\
\text { phage }\end{array}$ & Mixed \\
\hline $\begin{array}{l}\text { Human lung } \\
\text { Type I }\end{array}$ & Mouse & 54 & 267 & 13 \\
Type II & Human & 147 & 13 & 19 \\
Human placenta & & & & \\
$\quad$ Type I & Mouse & 5 & 221 & 15 \\
Type II & Human & 201 & 28 & 22 \\
MIA PaCa & & & & \\
Type I & Mouse & 2 & 139 & 8 \\
Type II & Human & 108 & 11 & 15 \\
Cervical carcinoma & & & & \\
Type I & Mouse & 2 & 16 & 5 \\
Type II & Human & 136 & 14 & 9 \\
Leukocyte & & & & \\
Type I & Mouse & 2 & 36 & 1 \\
Type II & Human & 66 & 2 & 7 \\
\hline
\end{tabular}

Morphology of colonies. Types I and II CSF from the different sources were used after the gel filtration step. Table I shows a summary of the morphology of colonies grown from mouse marrow in the presence of type I and from human marrow with type II CSF. Type I CSF predominantly yields colonies of macrophages, although most of the colonies grown in the presence of type II CSF are granulocytic.

\section{DISCUSSION}

The studies described herein were prompted by the finding of two distinct types of CSF in conditioned medium prepared from cultured human pancreatic carcinoma (MIA PaCa-2) (9): one high molecular weight CSF more active in mouse marrow and another, smaller molecular weight CSF active in human marrow. This finding had not been observed in our earlier work on human lung (7). The results of our studies using isoelectrofocusing in the initial purification suggest that previously used purification procedures resulted in significant losses of type II or human active CSF. Furthermore, it was uncertain whether the activities in mouse and human marrow represented one or two separate molecular species of CSF. Our studies clearly demonstrate the presence in human tissues of two distinct types of CSF widely separable by isoelectrofocusing. Type I has mol wt 50,000, exhibits greater activity in mouse marrow, and yields predominantly macrophagic colonies. Type II CSF ha mol wt 27,000 , is more active in human marrow, and yields mostly granulocytic colonies. The heterogeneity of type I CSF on isoelectrofocusing has been shown to be the result of different content of sialic acid because treatment with neuraminidase reduces type I CSF to one peak with a PI of 4.7.

The nonequivalence of mouse and human marrow culture in the assay of CSF has been described earlier. Thus, mouse bone marrow formed colonies in response to human plasma, urine, or feeder layer prepared from human leukocytes, whereas human marrow formed colonies only in the presence of feeder layer (13). More recently, Stanley (14) identified a subclass of CSF from murine $\mathrm{L}$ cell that stimulates the production of macrophages.

The biological significance of the existence of distinct types of CSF with different functions and specificities in vitro remains uncertain. A number of important and fundamental questions are raised by these observations. Why should a given CSF be more active in mouse than in human marrow or vice versa? What determines the type of colonies a given CSF stimulates? What is the relation of in vitro activity to what might be obtained in vivo? Detailed biochemical and immunological studies of highly purified preparations of these two types of CSF should provide the answers to some of these and other important questions. The availability of CSF-secreting permanent human cell lines such as MIA PaCa-2 should provide an excellent source of CSF for these objectives. Thus far, type I CSF has been purified to homogeneity (9) and the purification of type II CSF is well in progress.

\section{ACKNOWLEDGMENTS}

The authors express their sincere thanks to Dr. Alan M. Miller for preparing human marrow cells used in the assay, and to John K. Cini and Louise Stoudemire for their excellent technical assistance.

This work was supported in part by U. S. Public Health Service grants AM 09001, AM 26207, and RR 00261.

\section{REFERENCES}

1. Metcalf, D. 1973. The colony stimulating factor (CSF). In Humoral Control of Growth and Differentiation. J. LoBue and A. S. Gordon, editors. Academic Press, Inc., New York. 1: 91-118.

2. Guez, M., and L. Sachs. 1973. Purification of the protein that induces cell differentiation to macrophages and granulocytes. FEBS (Fed. Eur. Biochem. Soc.) Lett. 37: 149-154.

3. Burgess, A. W., J. Camakaris, and D. Metcalf. 1977. Purification and properties of colony-stimulating factor from mouse lung conditioned medium. J. Biol. Chem. 252: 1998-2006.

4. Stanley, E. R., and P. M. Heard. 1977. Factors regulating macrophage production and growth. J. Biol. Chem. 252: 4305-4312. 
5. Waheed, A., and R. K. Shadduck. 1979. Purification and properties of L cell-derived colony stimulating factor. J. Lab. Clin. Med. 94: 180-194.

6. Stanley, E. R., G. Hansen, J. Woodcock, and D. Metcalf. 1975. Colony stimulating factor and the regulation of granulopoiesis and macrophage production. Fed. Proc. 34: $2272-2278$.

7. Fojo, S. S., M-C. Wu, M. A. Gross, Y. Purcell, and A. A. Yunis. 1978. Purification and characterization of a colony stimulating factor from human lung. Biochemistry. 17: $3109-3116$.

8. Yunis, A. A., G. K. Arimura, and D. J. Russin. 1977. Human pancreatic carcinoma (MIA PaCa-2) in continuous culture: sensitivity to asparaginase. Int. J. Cancer. 19: $128-135$.

9. Wu, M-C., J. K. Cini, and A. A. Yunis. 1979. Purification of a colony-stimulating factor from cultured pancreatic carcinoma cells. J. Biol. Chem. 254: 6226-6228.

10. Fojo, S. S., M-C. Wu, M. A. Gross, and A. A. Yunis. 1977.
The isolation and characterization of a colony stimulating factor from human lung. Biochim. Biophys. Acta. 494: 92-99.

11. Wu, M-C., G. K. Arimura, and A. A. Yunis. 1977. Purification and characterization of a plasminogen activator secreted by cultured human pancreatic carcinoma cells. Biochemistry. 16: 1908-1913.

12. Kurland, J. I., R. S. Bockman, H. E. Broxmeyer, and M. A. S. Moore. 1978. Limitation of excessive myelopoiesis by the intrinsic modulation of macrophage derived prostaglandin E. Science (Wash. D. C.). 199: 552-555.

13. Lind, D. E., M. L. Bradley, F. W. Gunz, and P. C. Vicent. 1974. The nonequivalence of mouse and human marrow culture in the assay of granulopoietic stimulatory factors. J. Cell. Physiol. 83: 35-42.

14. Stanley, E. R. 1979. Colony stimulating factor (CSF) radioimmunoassay: detection of a CSF subclass stimulating macrophage production. Proc. Natl. Acad. Sci. U. S. A. 76: 2969-2973. 